\title{
Novel nano-rough polymers for cartilage tissue engineering
}

This article was published in the following Dove Press journal:

International Journal of Nanomedicine

15 April 2014

Number of times this article has been viewed

\author{
Ganesan Balasundaram' \\ Daniel M Storey' \\ Thomas J Webster ${ }^{2,3}$ \\ 'Surfatek, Longmont, CO, USA; \\ ${ }^{2}$ Department of Chemical Engineering, \\ Northeastern University, Boston, \\ MA, USA $;{ }^{3}$ Center of Excellence \\ for Advanced Materials Research, \\ King Abdulaziz University, Jeddah, \\ Saudi Arabia
}

\begin{abstract}
This study presents an innovative method for creating a highly porous surface with nanoscale roughness on biologically relevant polymers, specifically polyurethane (PU) and polycaprolactone (PCL). Nanoembossed polyurethane (NPU) and nanoembossed polycaprolactone (NPCL) were produced by the casting of PU and PCL over a plasma-deposited, spiky nanofeatured crystalline titanium (Ti) surface. The variables used in the process of making the spiky Ti surface can be altered to change the physical properties of the spiky particles, and thus, the cast polymer substrate surface can be altered. The spiky Ti surface is reusable to produce additional nanopolymer castings. In this study, control plain PU and PCL polymers were produced by casting the polymers over a plain Ti surface (without spikes). All polymer surface morphologies were characterized using both scanning electron microscopy and atomic force microscopy, and their surface energies were measured using liquid contact angle measurements. The results revealed that both NPU and NPCL possessed a higher degree of nanometer surface roughness and higher surface energy compared with their respective unaltered polymers. Further, an in vitro study was carried out to determine chondrocyte (cartilage-producing cells) functions on NPU and NPCL compared with on control plain polymers. Results of this study provided evidence of increased chondrocyte numbers on NPU and NPCL compared with their respective plain polymers after periods of up to 7 days. Moreover, the results provide evidence of greater intracellular protein production and collagen secretion by chondrocytes cultured on NPU and NPCL compared with control plain polymers. In summary, the present in vitro results of increased chondrocyte functions on NPU and NPCL suggest these materials may be suitable for numerous polymer-based cartilage tissue-engineering applications and, thus, deserve further investigation.
\end{abstract}

Keywords: chondrocytes, polyurethane, polycaprolactone, nano-roughened polymers, cartilage applications

\section{Introduction}

With an aging population and the growing problem of obesity, the number of osteoarthritis cases is estimated to boom in the coming years. ${ }^{1-6}$ At this time, more than 250,000 knee and hip replacements are performed in the United States each year for end-stage disease joint failure, and many other patients suffer from less severe cartilage damage. $^{7-13}$ In addition, with a more active adult population, cartilage damage resulting from sports injuries can often result in premature cartilage degeneration. Although damage to cartilage may appear to be an easy problem to tackle, it is not, because the tissue is avascular and contains very few cells, has a complex structure, exhibits a high degree of heterogeneity, and functions under an intensely strenuous environment. As
Correspondence: Thomas J Webster Department of Chemical Engineering, Northeastern University, 360 Huffington Avenue, Boston, MA 02115, USA

Email th.webster@neu.edu 
cartilage tissue has a limited capacity for natural regeneration, it is clear that osteoarthritis (commonly referred to as the "wear-and-tear" disease of cartilage because the ability of cartilage to regenerate or "heal" itself decreases with age) is one of the ten most disabling diseases in developed countries. $^{1}$

To date, a wide range of natural and synthetic materials has been investigated as scaffolding for cartilage repair. Natural polymers that have been explored as bioactive scaffolds for cartilage tissue engineering include alginate, agarose, fibrin, hydroxyapatite (HA), collagen, gelatin, chitosan, chondroitin sulfate, and cellulose. ${ }^{11-16}$ Natural polymers can often interact with cells via cell surface receptors to regulate or direct cell functions. However, because of this interaction, these polymers may also stimulate an immune system response; thus, antigenicity and disease transfer are of concern when using these biomaterials. In addition, natural polymers may be inferior mechanically and be subject to variable enzymatic host degradation. In contrast, synthetic polymers are more controllable and predictable, where chemical and physical properties of a polymer can be modified to alter mechanical and degradation characteristics.

Numerous synthetic scaffolding materials have been used for cartilage regeneration. In particular, polyurethane (PU) is a major class of synthetic elastomers that has been evaluated for a variety of medical implants, and particularly for long-term implants because of its good biocompatibility properties. ${ }^{17-19}$ PU offers many advantages in the design of biodegradable polymer composites. It also offers substantial opportunities to tailor polymer structures to achieve a broad range of mechanical properties. A number of studies indicate that the biocompatibility of degradable PU appears to be satisfactory on the basis of both in vitro and in vivo studies. ${ }^{17-19}$ Animal studies showed rapid cell in-growth with no adverse tissue reactions when using PU. ${ }^{19}$

Polylactones or polycaprolactone (PCL) are two other widely studied synthetic polymers for cartilage repair. ${ }^{20-24}$ PCL is a semicrystalline polymer with a glass transition temperature of about $-60^{\circ} \mathrm{C}$. The polymer has a low melting temperature $\left(59^{\circ} \mathrm{C}-64^{\circ} \mathrm{C}\right)$ and is compatible with a range of other polymers. The PCL homopolymer has a degradation time on the order of 2-3 years. ${ }^{21}$ PCL is considered nontoxic and a tissue-compatible material. Blends with other polymers, block copolymers, and low-molecular weight polyols and macromers based on the caprolactone backbone are a few possible strategies. ${ }^{24}$ However, these synthetic polymers, in the form they are used today, do not mimic the nanotopographical features that collagen and other extracellular matrix proteins create in cartilage tissue. In the pursuit of more "cell-friendly" polymeric surfaces, many physical and chemical methods have been developed to increase surface tension and surface roughness. ${ }^{25-29}$ In these pursuits, many studies have turned to harsh chemicals to create nanoscale surface features such as strong acids $\left(\mathrm{HNO}_{3}\right.$ and $\left.\mathrm{HCl}\right)$, strong bases $(\mathrm{NaOH})$, salt doping $(\mathrm{NaCl})$ followed by aqueous sonication, freeze drying, and various electrospinning methods. Although the methods listed here have shown significant progress in increasing chondrocyte cell adhesion and growth, they have some obvious drawbacks. First, great strides must be taken to wash substrates after acidic and basic treatments to ensure $\mathrm{pH}$ neutrality has been reached before cell experiments. A similar precaution must be taken after $\mathrm{NaCl}$ doping is performed. If the salt contained in the polymer substrate is not removed before cell seeding, the potential for osmotic pressure changes throughout use (because of late eluting salts) can cause health consequences. With this in mind, lengthy sonication steps in deionized water are required. In addition, some of the other methods mentioned are laborintensive and require a significant amount of practice before they can be used to perfect the process (such as electrospinning), preventing them from truly being a "high-throughput" method for developing polymers with nano-roughened surfaces for tissue engineering applications.

For all of the these reasons, the goal of this in vitro study was to produce biocompatible nanostructured polymeric surfaces (particularly for PU and PCL) to increase chondrocyte functions that could be created at both the industrial and laboratory scales without the use of any additional chemicals or complicated synthesis routes.

\section{Materials and methods Polymer scaffold preparation}

Before polymer scaffold preparation, the surface of stainless steel $\left(300 \mathrm{~cm}^{2}\right.$ rectangular sheets of 316L; Alfa Aesar, New York, NY, USA) coated with titanium (Ti) spikes was prepared by a proprietary nano-plasma deposition process (Figure 1A). It is possible to manipulate process variables to change the shape of the Ti spiked particles on the stainless steel. The coated Ti spikes are highly firm and do not produce any particle debris during the subsequent nanopolymer sheet fabrication process.

The fabrication process of the nanopolymer film is illustrated in Figure 1. PU (Tecoflex, medical grade SG93A; 90-140 × 10 $0^{3}$ MW; Lubrizol Advanced Materials 
A

B

Ti spikes on stainless steel kept in a glass dish

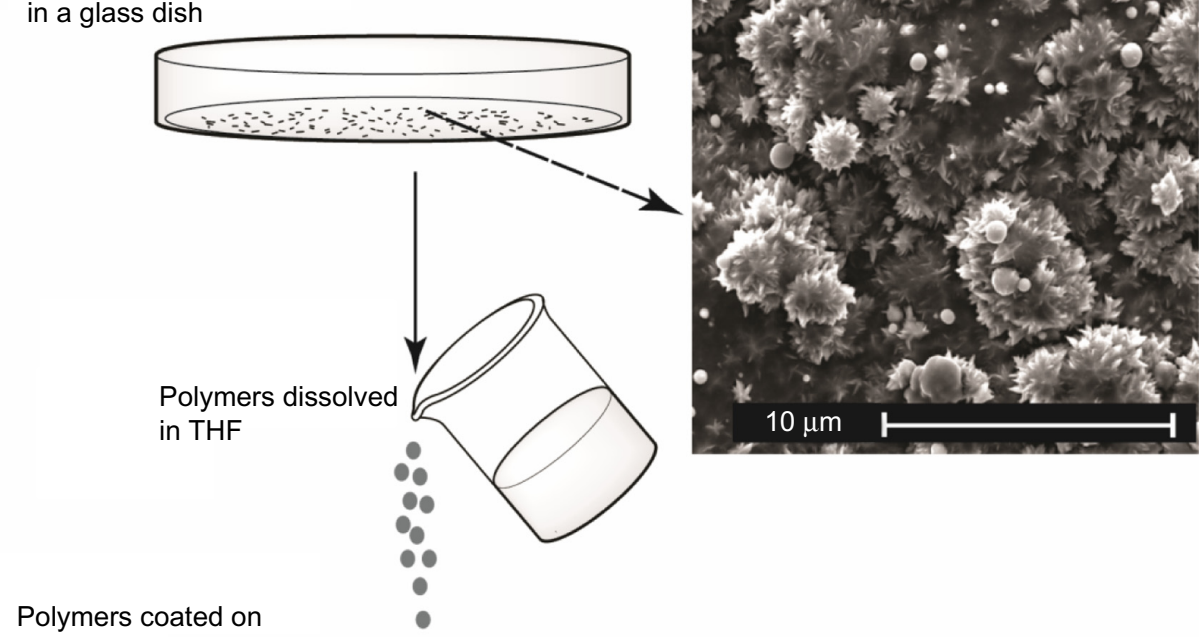

Ti spikes

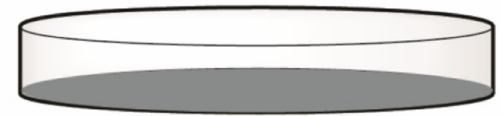

1. Dried overnight in a fumehood

2. Dried polymer removed carefully and further dried in vacuum oven

C

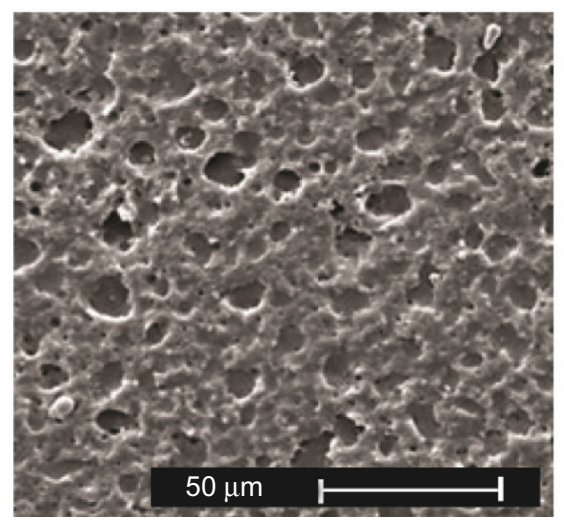

Figure I Schematic illustration of nanoembossed polyurethane and nanoembossed polycaprolactone synthesis using a Titianium (Ti) spike template created on stainless steel (A). Scanning electron microscopy image of Ti spikes created on stainless steel (B). Scanning electron microscopy images of the synthesized nanoembossed polyurethane polymer, using the above method (C).

Abbreviation: THF, tetrahydrofuran.

Inc., Wilmington, MA, USA) and PCL $\left(10-20 \times 10^{3}\right.$ MW; Polysciences Inc., Warrington, PA, USA) films were fabricated separately by dissolving the polymers $(1.6 \mathrm{~g}$ $\mathrm{PU}$ and $0.5 \mathrm{~g}$ PCL) in 30 and $8 \mathrm{~mL}$ tetrahydrofuran (99\%; Sigma, St Louis, MO, USA), respectively, for approximately 1 hour at $50^{\circ} \mathrm{C}$. The resulting polymer solutions were separately poured into glass petri dishes that contained the Ti-spiked coated stainless steel templates and were left partially covered at room temperature for 24 hours to allow the THF (tetrahydrofuran) to evaporate. The nanopolymer sheets were carefully removed by hand and further dried for 48 hours in a vacuum oven (15 in $\mathrm{Hg}$ ), followed by a brief sonication in deionized water. Finally, polymer scaffolds $(10 \times 5 \times 0.5 \mathrm{~mm})$ were cut from the resulting PU and PCL bulk polymer films, using a surgical knife. Plain polymer films were prepared in a similar manner except that the 
Ti-spiked templates were not used. PCL and PU substrates were sterilized overnight by exposure to ultraviolet light, according to standard techniques.

\section{Polymer scaffold characterization}

Scanning electron microscopy (SEM) measurements were made on the polymer substrates after sputter-coating with a thin layer of gold, using a Hummer V Sputter Coater (Anatech USA, Union City, CA, USA) in a 200-mTorr vacuum in argon for 3 minutes at $20 \mathrm{~mA}$. Images were taken using a Tescan MIRA/LSM SEM (Tescan Orsay Holding, Kohoutovice, Czech Republic) at a $20-\mathrm{kV}$ accelerating voltage. Digital images were recorded using the Tescan-MIRA software. Surface roughness was quantified using a XE-150 Atomic Force Microscope from Park Systems (Santa Clara, CA, USA). A scan rate, typically $1 \mathrm{~Hz}$, was used at a selected scanning point to obtain root mean square roughness values. Atomic force microscopy analysis was performed in ambient air.

Average contact angle measurements and surface energy calculations were performed using the VCA optima XE system (AST Productions Inc., Billerica, MA, USA). Deionized water and diiodomethane (99\%; Sigma Aldrich, St Louis, MO, USA) were used to gain information for both the polar and dispersive force components so that the surface energy could be obtained. Droplets of the solvent that were $1.00 \mu \mathrm{L}$ in size were deposited on each of the substrates, and the left and right droplet angles were measured using the VCA optima software after 10 seconds. Averages of ten droplets were taken from each substrate, and surface energies were calculated using the method of geometric means.

\section{Cell density assay}

All substrates were sterilized under ultraviolet light for 4 hours before the cell experiments. Human articular chondrocytes (cartilage-synthesizing cells; Cell Applications Inc., Boston, MA, USA) were cultured in chondrocyte growth medium (Cell Applications Inc.,) on 100-mm Petri dishes (VWR International, New York, NY, USA). Cells were incubated under standard cell culture conditions (specifically, a sterile, humidified, $5 \% \mathrm{CO}_{2}, 95 \%$ air, $37^{\circ} \mathrm{C}$ environment), seeded at a density of 50,000 cells $/ \mathrm{cm}^{2}$ for all experiments, and were allowed to attach and grow for periods of 1, 4, and 7 days. Chondrocytes used for the following experiments were at passage numbers lower than 10. At the end of each time, nonadherent cells were removed by rinsing with a phosphate buffered saline solution. The remaining cells were fixed with formaldehyde (Sigma Aldrich), stained with Hoescht
33258 dye (Sigma Aldrich), and counted under a fluorescence microscope (Leica, DM IRB, Chicago, IL, USA). Five random fields were counted per substrate.

\section{Total intracellular protein}

The total number of intracellular proteins from the chondrocyte lysates was determined using a commercially available kit (BCA Protein Assay Reagent Kit; Pierce Biotechnology, St Louis, MO, USA) with a microplate reader and a Molecular Devices SpectraMax 190 spectrophotometer with SoftMax Pro software (Molecular Devices, St Louis, MO, USA). Following the manufacturer's instructions, the protein-eluted solution was mixed with copper sulfate and bicinchoninic acid and incubated at $37^{\circ} \mathrm{C}$ for 30 minutes. This process allowed for reduction of $\mathrm{Cu}^{+2}$ to $\mathrm{Cu}^{+1}$ by a protein (if present) in an alkaline environment, and the cuprous cation could be detected colorimetrically via an agent containing bicinchoninic acid. Absorbance was measured at $562 \mathrm{~nm}$ on the plate reader. The amount of protein adsorbed onto each surface was determined by comparing measurements with a standard curve obtained from the light absorbance of predetermined albumin (Pierce Biotechnology) concentrations. The total amount of protein was normalized to cell number and volume.

\section{Total intracellular collagen}

For intracellular collagen concentration measurements, the Sirius Red dye (Direct Red; Sigma Aldrich) was used to stain collagen, and a spectrophotometer was used to determine the concentration. For this purpose, the cells were lysed using freeze-thaw methods. Specifically, the cell extracts $(50 \mathrm{~mL} /$ well $)$ were placed in 96-well plates in triplicate per substrate type. The plates were placed in a humidified incubator (at $37^{\circ} \mathrm{C}$ ) for 16 hours and then in a dry incubator (at $37^{\circ} \mathrm{C}$ ) with desiccant. Each well was washed with $200 \mathrm{~mL}$ $\mathrm{dH}_{2} \mathrm{O}$ three times for 1 minute per wash. In each well, 100 $\mathrm{mL} 0.1 \%$ Sirius Red stain (0.05 g Sirius Red powder per 50 $\mathrm{mL}$ picric acid) was allowed to sit for 1 hour at room temperature. Using $200 \mathrm{~mL} 0.1 \mathrm{M} \mathrm{HCl}$, the plates were washed five times for 10 seconds per wash. The stain was then washed with $200 \mathrm{~mL} 0.1 \mathrm{M} \mathrm{NaOH}$ for 5 minutes and mixed well. The stain was placed into a second plate to read the absorbance in a microplate reader at $540 \mathrm{~nm}$. A standard curve was constructed as micrograms of collagen versus absorbance at 540 $\mathrm{nm}$. For the standard curve, a $0.1 \%$ collagen type I solution (Sigma Aldrich) was diluted at small increments, and the light absorbance of the Sirius Red stain in these dilutions was recorded. The total amount of collagen was normalized to cell number and volume. 


\section{Statistics}

All experiments were conducted in triplicate, with at least three repeats each, and data were analyzed via analysis of variance, followed by Student's $t$-tests.

\section{Results}

\section{Substrate preparation and characterization}

The preparation of a nanoembossed polymer surface on $\mathrm{Ti}$ spikes created by nano-plasma deposition is a new approach presented in this study that does not require any special chemicals or sophisticated equipment (Figure 1). Figure 2 provides SEM pictures of the different treatments, which gave rise to different nanotopographies on the sample surfaces. AFM data of all the polymer scaffolds were characterized by root mean square measurements (Table 1). Distinct topographical differences were observed on the plain and nanoembossed polymer scaffolds. Specifically, nanoembossed polymer scaffolds exhibited considerably more surface roughness (Figure 2). The differences resulting from the
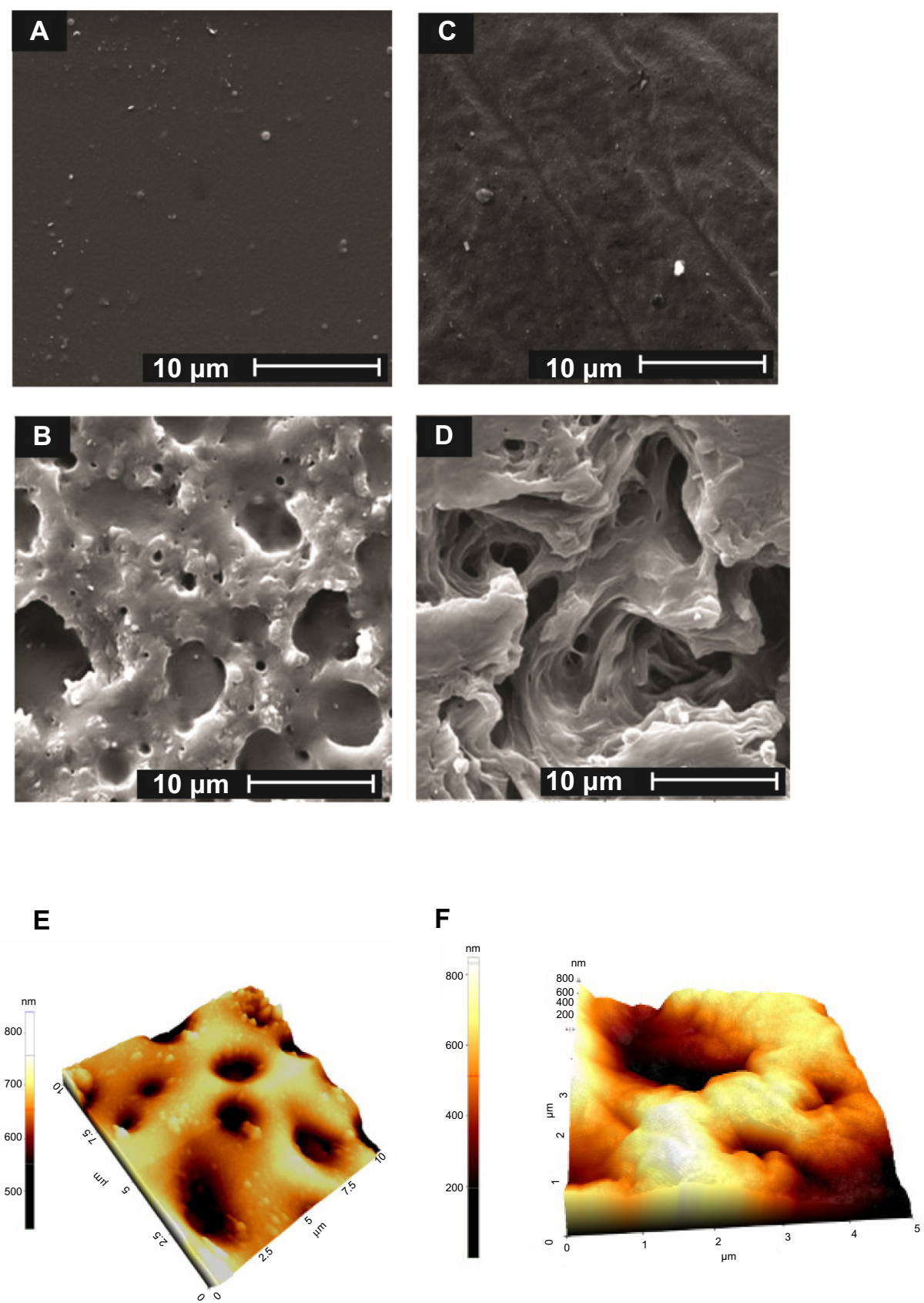

Figure 2 Low- and high-magnification scanning electron microscopy images of nanoembossed polyurethane (A and $\mathbf{B})$ and nanoembossed polycaprolactone synthesis $(\mathbf{C}$ and $\mathbf{D})$. Atomic force microscopy images of nanoembossed polyurethane and nanoembossed polycaprolactone synthesis (E and $\mathbf{F})$. 
Table I Surface roughness of the materials of interest

\begin{tabular}{lll}
\hline Surfaces & $\begin{array}{l}\text { Average root mean } \\
\text { square values }(\mathbf{n m})\end{array}$ & $\begin{array}{l}\text { Standard } \\
\text { deviation } \mathbf{( n m})\end{array}$ \\
\hline Plain polyurethane & 2.7 & 1.0 \\
Nanopolyurethane & 155.8 & 6.3 \\
Plain polycaprolactone & 2.9 & 1.8 \\
Nanopolycaprolactone & 80.2 & 3.7 \\
\hline
\end{tabular}

embossing of polymers on the Ti spikes suggest that the polymers had more and larger pores compared with nonembossed polymers. Specifically, the average root mean square roughness of the nanoembossed polyurethane (NPU) was 155.8 $\mathrm{nm}$, where plain PU displayed a roughness of $2.7 \mathrm{~nm}$ (for 1 $\times 1 \mu \mathrm{m}$ AFM scans; Table 1). A similar trend was observed between nanoembossed polycaprolactone (NPCL) and PCL scaffolds. Specifically, NPCL and plain PCL displayed a roughness of 80.2 and $2.9 \mathrm{~nm}$, respectively. Interestingly, among the scaffolds (PU and PCL), although there were similar roughness values measured ( 2.7 and $2.9 \mathrm{~nm}$, respectively) for plain polymers, a two times greater difference in root mean square was observed between the NPU and NPCL ( 80.2 and $155.8 \mathrm{~nm}$, respectively).

The water contact angle is the inner angle formed by a drop of water with the surface that generally provides a quantitative expression for wetting. It is one of the parameters used to measure the hydrophilicity of the surface, and therefore, it was measured before and after surface treatments. Water contact angle values for the nanoembossed polymers were all statistically different from the unembossed surfaces (Figure 3). The results showed that an increasing surface tension value was directly correlated to a decrease in liquid contact angles on the surfaces of the NPU $\left(32^{\circ}\right)$ and

\section{A}

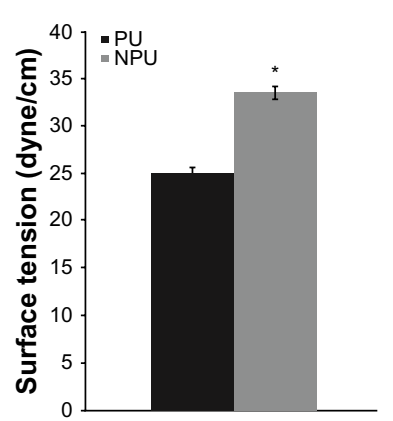

B

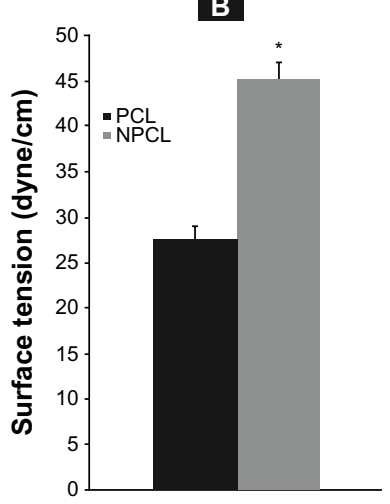

Figure 3 Surface tension data of the nanoembossed polyurethane $(\mathbf{A})$ and nanoembossed polycaprolactone synthesis (B) compared with their corresponding plain polymer surfaces. All values are statistically different than each other $(* P<0.01)$. Abbreviations: PU, polyurethane, PCL, polycaprolactone; NPU, nanoembossed polyurethane; NPCL, nanoembossed polycaprolactone.
NPCL $\left(20^{\circ}\right)$ compared with PU $\left(75^{\circ}\right)$ and PCL $\left(69^{\circ}\right)$. NPU and NPCL had a $34 \%$ and $45 \%$ increase in surface energy compared with respective plain polymers. This increase in surface energy can be directly related to the change in the topography at the polymer surface. The morphology changes resulting from nanoembossing create a more hydrophilic surface, thus decreasing the effective contact angle of the droplets.

\section{Chondrocyte numbers}

At 1 day, significantly greater numbers of chondrocytes were observed on NPU and NPCL compared with PU and PCL, respectively (Figure 4A and B). This trend continued as chondrocyte numbers were greater on nanoembossed scaffolds (for NPU and NPCL) compared with unembossed scaffolds after 4 and 7 days. Particularly, NPCL displayed more than two times the number of chondrocytes from day 1 through day 7 .

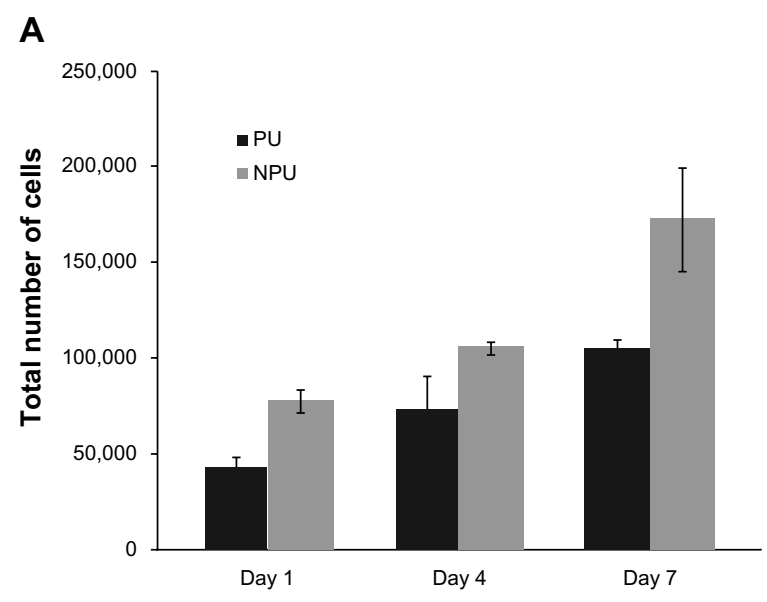

\section{B}

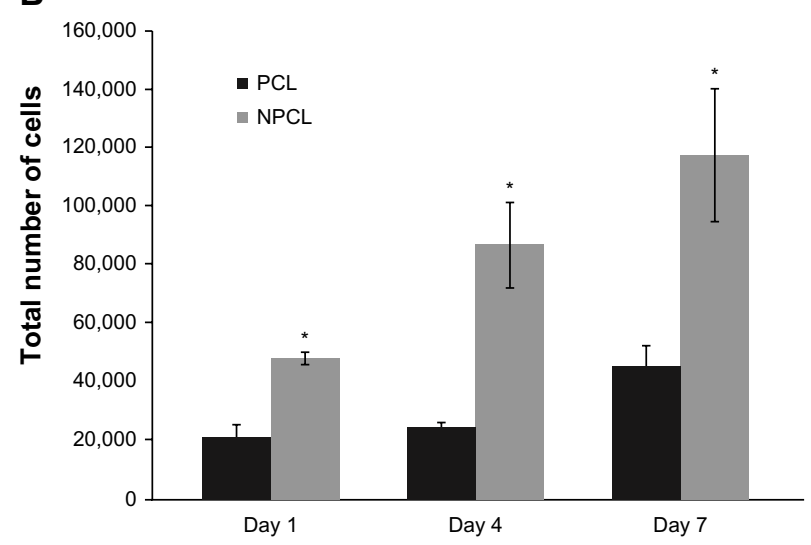

Figure 4 Increased chondrocyte density on nanoembossed polyurethane (A) and nanoembossed polycaprolactone (B) after I, 4, and 7 days. Data = mean \pm SEM; $\mathrm{n}=3$. All values are statistically different from each other at the same time and are statistically different on the same substrate with time $(* P<0.0 \mathrm{I})$.

Abbreviations: PU, polyurethane, PCL, polycaprolactone; NPU, nanoembossed polyurethane; NPCL, nanoembossed polycaprolactone; SEM, standard error of the mean. 


\section{Extracellular matrix component synthesis}

To observe longer-term chondrocyte functions, total intracellular protein, and total intracellular collagen content, studies were conducted as previously stated. The results demonstrated that compared with nonembossed polymer scaffolds, chondrocytes cultured on nanoembossed polymers synthesized greater amounts of total intracellular protein, as shown in Figure 5. Specifically, significantly greater amounts of total intracellular proteins were measured on nanoembossed compared with plain polymer scaffolds on day 7 . No statistical differences were observed among the two polymer scaffolds (PU/PCL and NPU/NPCL).

As demonstrated in Figure 6, intracellular collagen was synthesized at significantly larger amounts when chondrocytes were cultured on nanoembossed polymer scaffolds compared with nonembossed polymer scaffolds on day 7 . Specifically, the amount of collagen on the NPU scaffold was $300 \mu \mathrm{g}$ more than that on the PU scaffold, whereas an additional $500 \mu \mathrm{g}$ of collagen was found on NPCL compared with PCL scaffolds. The amount of collagen produced on NPCL was more than three times that on PCL scaffolds after 7 days. Although the PCL scaffold displayed less than two times the amount of collagen production compared with $\mathrm{PU}$ scaffolds, it displayed similar levels of collagen production after surface nanomodification.

\section{Discussion}

A successful, easy-to-produce scaffold for cartilage reconstruction has not yet been identified. Potentially, such a scaffold might be produced from polymers (such as PU and PCL) that have been documented as being compatible with

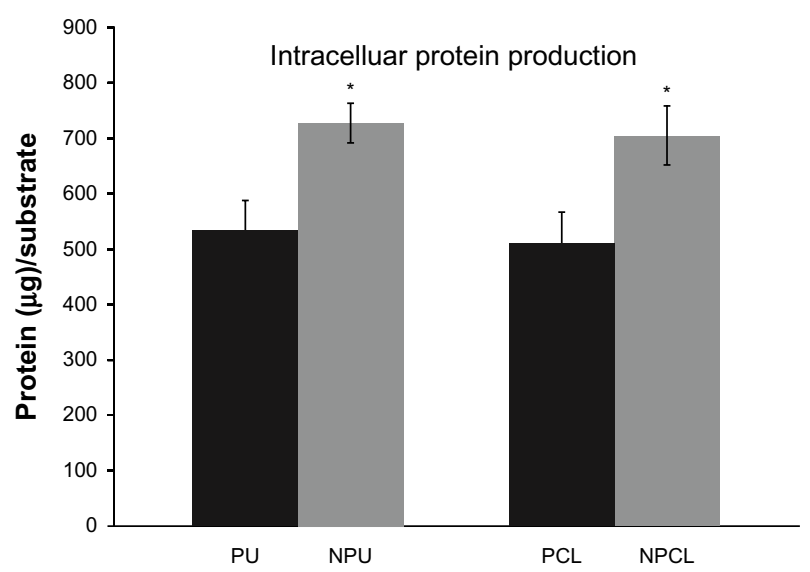

Figure $\mathbf{5}$ Increased intracellular protein production on nanoembossed polyurethane (A) and nanoembossed polycaprolactone (B) after 7 days. Data $=$ mean \pm SEM; $n=3$. All values are statistically different from each other at the same time $(* P<0.0 \mathrm{I})$. Abbreviations: PU, polyurethane, PCL, polycaprolactone; NPU, nanoembossed polyurethane; NPCL, nanoembossed polycaprolactone.

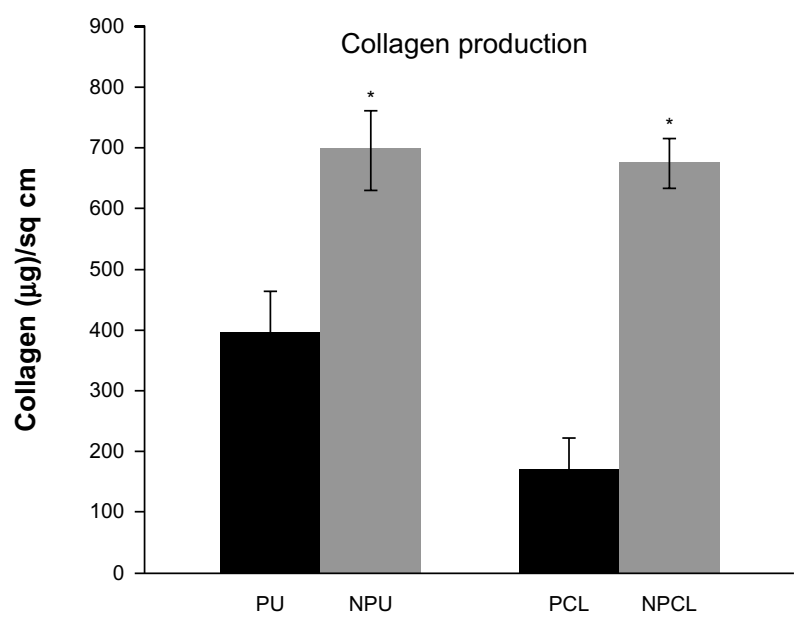

Figure 6 Increased intracellular collagen production on nanoembossed polyurethane (A) and nanoembossed polycaprolactone (B) after 7 days. Data $=$ mean \pm SEM; $n=3$. All values are statistically different from each other at the same time $\left({ }^{*} P<0.01\right)$.

Abbreviations: PU, polyurethane, PCL, polycaprolactone; NPU, nanoembossed polyurethane; NPCL, nanoembossed polycaprolactone; SEM, standard error of the mean.

various tissues and cells. The present research, thus, had two goals: synthesize body-friendly nanostructured polymer scaffolds for cartilage tissue engineering, and compare select cell functions on these scaffolds with respective conventional polymer scaffolds having nanosmooth surface features. To meet these goals, the present study created novel polymer scaffolds (PU and PCL) having nanostructured surface topographies and interconnected pores without any traditional chemical treatment. Nano-roughness on the polymer scaffolds was achieved by embossing the scaffolds (prepared using a THF colloidal solution) on Ti spikes (created using our proprietary nano-plasma deposition technologies), followed by drying. Nanodimensional surface features were confirmed by SEM and AFM analysis. Surface tension properties of the nanoembossed and plain polymer surfaces were characterized by contact angle measurements. Cellular experiments on these polymeric scaffolds provided evidence that nanoembossed polymer scaffolds greatly influenced chondrocyte behavior. Not only did the cell numbers increase on nanoembossed scaffolds, but subsequent functions of chondrocytes (such as intracellular protein and collagen synthesis) were enhanced as well. The basis of these phenomena can be attributed to the altered surface properties for the polymer because no chemical change resulted during nanomodification.

In the past, several people have reported alterations in cellular functions as a result of nanosurface modification. ${ }^{25-29}$ For example, Dalby et al observed increased fibroblast adhesion on nano-rough polymers,$^{29}$ whereas Miller et al reported increased endothelial and vascular smooth muscle cell 
functions on nano-roughened polymer films. ${ }^{30}$ More pertinent to the present study, Park et $\mathrm{al}^{26}$ observed enhanced chondrocyte functions on nanometer PLGA (poly(lactic-co-glycolic) acid) and Kay et al observed increased osteoblast and chondrocyte density on NaOH-treated two-dimensional PLGA films. ${ }^{28}$ Thapa et al reported increased bladder smooth muscle cell adhesion and growth on nano-rough PLGA films. ${ }^{31}$ However, in all of these studies, researchers either used polymer demixing techniques (which would only occur for a select number of polymers) or chemicals to modify the polymer surface roughness to create nanometer features.

In contrast, several studies have demonstrated the effects of surface nanotopography alone without changing chemistry (or other polymer properties) on the functions of cells. For example, Thapa et al achieved nanometer PLGA surface roughness values without a change in chemistry via silastic casting techniques. ${ }^{31,32}$ Specifically, $\mathrm{NaOH}$ treatment of PLGA was initially applied to create a desired roughness on the surface. Then, a silastic mold was fabricated using this $\mathrm{NaOH}$-treated PLGA surface. The silastic mold was used to cast PLGA films to possess nanometer roughness features without chemical changes. Most important, this process eliminated the chemistry differences on the PLGA substrates to allow an investigation of surface roughness on cellular functions. Results indicated that bladder smooth muscle cell density increased on PLGA films with nanometer compared with traditional micron surface roughness. ${ }^{31,32}$ Similarly, Miller et $\mathrm{al}^{30}$ observed enhanced vascular smooth muscle cell functions on substrates created using the same technique as Thapa et al. ${ }^{31}$ However, they did not study chondrocyte functions on such substrates, and such polymers were films, not porous scaffolds.

Regardless of the methods discussed here (chemical or nonchemical), it is ultimately the ability of proteins to bind differently to nano- and micro-rough surfaces that will influence cellular functions. For example, because of changes in surface wettability, some proteins preferentially adsorb to materials with greater surface nanometer features; thus, the type, amount, conformation, and so on of proteins adsorbed from cell culture media could have been different in the present study on PU PCL modified to have nanometer surface features; this must be studied in detail in the future. In support of this claim, Miller et al reported increased adsorption of vitronectin on nanodimensional PLGA surfaces compared with microdimensional PLGA surfaces. ${ }^{33}$ This increase in vitronectin adsorption was directly linked to increased cellular functions on the nanodimensional PLGA films. If a similar pathway is considered, the increased chondrocyte adhesion, growth, and total extracellular matrix production observed on the present nanoembossed scaffolds could have been caused, in part, by an increase in the adsorption of proteins that attract chondrocytes.

\section{Conclusion}

In summary, PU and PCL scaffolds having nano-rough surface topographies were successfully created in the present study with a single-step nanoembossing process on Ti created to possess nanodimensional spikes. In vitro cell testing on these materials using human chondrocytes provided direct evidence that chondrocyte density and protein production were increased on nanoembossed scaffolds compared with conventional, plain polymer scaffolds. Because of the already widespread use of polymers in cartilage applications, results of the present study suggest that nanoembossed polymers produced using this new method should be further considered for numerous cartilage tissue engineering applications.

\section{Disclosure}

The authors report no conflicts of interest in this work.

\section{References}

1. Brooks PM. Impact of osteoarthritis on individuals and society: how much disability? Social consequences and health economic implications. Curr Opin Rheumatol. 2002;14(5):573-577.

2. Lawrence RC, Felson DT, Helmick CG, et al; National Arthritis Data Workgroup. Estimates of the prevalence of arthritis and other rheumatic conditions in the United States. Part II. Arthritis Rheum. 2008; 58(1):26-35.

3. Dillon CF, Rasch EK, Gu Q, Hirsch R. Prevalence of knee osteoarthritis in the United States: arthritis data from the Third National Health and Nutrition Examination Survey 1991-94. J Rheumatol. 2006; 33(11):2271-2279.

4. Maetzel A, Li LC, Pencharz J, Tomlinson G, Bombardier C; Community Hypertension and Arthritis Project Study Team. The economic burden associated with osteoarthritis, rheumatoid arthritis, and hypertension: a comparative study. Ann Rheum Dis. 2004;63(4): 395-401.

5. Niu J, Zhang YQ, Torner J, et al. Is obesity a risk factor for progressive radiographic knee osteoarthritis? Arthritis Rheum. 2009;61(3): 329-335.

6. Sun BH, Wu CW, Kalunian KC. New developments in osteoarthritis. Rheum Dis Clin North Am. 2007;33(1):135-148.

7. Kuo CK, Li WJ, Mauck RL, Tuan RS. Cartilage tissue engineering: its potential and uses. Curr Opin Rheumatol. 2006;18(1):64-73.

8. Stoddart MJ, Grad S, Eglin D, Alini M. Cells and biomaterials in cartilage tissue engineering. Regen Med. 2009;4(1):81-98.

9. Kaufman MR, Tobias GW. Engineering cartilage growth and development. Clin Plast Surg. 2003;30(4):539-546.

10. Almarza AJ, Athanasiou KA. Design characteristics for the tissue engineering of cartilaginous tissues. Ann Biomed Eng. 2004;32(1): 2-17.

11. Redman SN, Oldfield SF, Archer CW. Current strategies for articular cartilage repair. Eur Cell Mater. 2005;9:23-32; discussion 23-32.

12. Chung C, Burdick JA. Engineering cartilage tissue. Adv Drug Deliv Rev. 2008;60(2):243-262. 
13. Becerra J, Andrades JA, Guerado E, Zamora-Navas P, López-Puertas JM, Reddi AH. Articular cartilage: structure and regeneration. Tissue Eng Part B Rev. 2010;16(6):617-627.

14. Gloria A, De Santis R, Ambrosio L. Polymer-based composite scaffolds for tissue engineering. J Appl Biomater Biomech . 2010;8(2):57-67.

15. Lu L, Zhu X, Valenzuela RG, Currier BL, Yaszemski MJ. Biodegradable polymer scaffolds for cartilage tissue engineering. Clin Orthop Relat Res. 2001;(Suppl 391):S251-S270.

16. Sohier J, Moroni L, van Blitterswijk C, de Groot K, Bezemer JM. Critical factors in the design of growth factor releasing scaffolds for cartilage tissue engineering. Expert Opin Drug Deliv. 2008;5(5):543-566.

17. de Groot JH. Polyurethane scaffolds for meniscal tissue regeneration. Med Device Technol. 2005;16(7):18-20.

18. Chia SL, Gorna K, Gogolewski S, Alini M. Biodegradable elastomeric polyurethane membranes as chondrocyte carriers for cartilage repair. Tissue Eng. 2006;12(7):1945-1953.

19. Tsui YK, Gogolewski S. Microporous biodegradable polyurethane membranes for tissue engineering. J Mater Sci Mater Med. 2009;20(8):1729-1741.

20. Alves da Silva ML, Martins A, Costa-Pinto AR, et al. Cartilage tissue engineering using electrospun PCL nanofiber meshes and MSCs. Biomacromolecules. 2010;11(12):3228-3236.

21. Li WJ, Danielson KG, Alexander PG, Tuan RS. Biological response of chondrocytes cultured in three-dimensional nanofibrous poly(epsiloncaprolactone) scaffolds. J Biomed Mater Res A. 2003;67(4): 1105-1114.

22. Eyrich D, Wiese H, Maier G, et al. In vitro and in vivo cartilage engineering using a combination of chondrocyte-seeded long-term stable fibrin gels and polycaprolactone-based polyurethane scaffolds. Tissue Eng. 2007;13(9):2207-2218.

23. Izquierdo R, Garcia-Giralt N, Rodriguez MT, et al. Biodegradable PCL scaffolds with an interconnected spherical pore network for tissue engineering. J Biomed Mater Res A. 2008;85(1):25-35.
24. Chang KY, Hung LH, Chu IM, Ko CS, Lee YD. The application of type II collagen and chondroitin sulfate grafted PCL porous scaffold in cartilage tissue engineering. J Biomed Mater Res A. 2010;92(2):712-723.

25. Khang D, Carpenter J, Chun YW, Pareta R, Webster TJ. Nanotechnology for regenerative medicine. Biomed Microdevices. 2010;12(4): 575-587.

26. Park GE, Pattison MA, Park K, Webster TJ. Accelerated chondrocyte functions on NaOH-treated PLGA scaffolds. Biomaterials. 2005;26(16):3075-3082.

27. Savaiano JK, Webster TJ. Altered responses of chondrocytes to nanophase PLGA/nanophase titania composites. Biomaterials. 2004; 25(7-8):1205-1213.

28. Kay S, Thapa A, Haberstroh KM, Webster TJ. Nanostructured polymer/ nanophase ceramic composites enhance osteoblast and chondrocyte adhesion. Tissue Eng. 2002;8(5):753-761.

29. Dalby MJ, Childs S, Riehle MO, Johnstone HJ, Affrossman S, Curtis AS. Fibroblast reaction to island topography: changes in cytoskeleton and morphology with time. Biomaterials. 2003;24(6):927-935.

30. Miller DC, Haberstroh KM, Webster TJ. Mechanism(s) of increased vascular cell adhesion on nanostructured poly(lactic-co-glycolic acid) films. J Biomed Mater Res A. 2005;73(4):476-484.

31. Thapa A, Miller DC, Webster TJ, Haberstroh KM. Nano-structured polymers enhance bladder smooth muscle cell function. Biomaterials. 2003;24(17):2915-2926.

32. Thapa A, WebsterTJ, Haberstroh KM. Polymers with nano-dimensional surface features enhance bladder smooth muscle cell adhesion. J Biomed Mater Res A. 2003;67(4):1374-1383.

33. Miller DC, Haberstroh KM, Webster TJ. PLGA nanometer surface features manipulate fibronectin interactions for improved vascular cell adhesion. J Biomed Mater Res A. 2007;81(3):678-684.
International Journal of Nanomedicine

\section{Publish your work in this journal}

The International Journal of Nanomedicine is an international, peerreviewed journal focusing on the application of nanotechnology in diagnostics, therapeutics, and drug delivery systems throughout the biomedical field. This journal is indexed on PubMed Central,

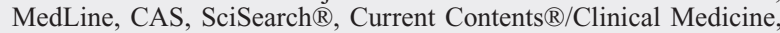

\section{Dovepress}

Journal Citation Reports/Science Edition, EMBase, Scopus and the Elsevier Bibliographic databases. The manuscript management system is completely online and includes a very quick and fair peer-review system, which is all easy to use. Visit http://www.dovepress.com/ testimonials.php to read real quotes from published authors. 